\title{
Conflito de Cosmovisões de Direitos Humanos: Universalismo vs. Relativismo e as Propostas Conciliatórias Multiculturalistas de Boaventura de Sousa Santos e Joaquín Herrera Flores
}

\begin{abstract}
Aline Memória de Andrade
Graduação em Direito pela Universidade Federal do Ceará com distinção Magna cum Laude (2015). Advogada com inscrição na Ordem dos Advogados do Brasil - Seccional Ceará. Mestranda em Direito pela Universidade Federal do Ceará (UFC). Especialização em Direito Processual Civil pela Faculdade Damásio (2017). Tem experiência na área de Direito, atuando principalmente nos seguintes temas: direito administrativo, direito constitucional, direito internacional, direito militar e direitos humanos. http://lattes.cnpq.br/2568027044548698. https://orcid.org/0000-0003-4024-8468. alinememoria@yahoo.com.br

\section{Glauco Barreira Magalhães Filho}

Graduação (1993) e Mestrado em Direito (2000) pela Universidade Federal do Ceará. Livre-docente em Filosofia do Direito pela Universidade Vale do Acaraú (2006). Doutorado em Sociologia pela UFC (2010) e em Ministério (Faculdade de Teologia Metodista Livre - Reconhecida pela Aetal). Doutorado e Especialização em Teologia Histórica e Dogmática pela Faerpi (2011). Graduação em Teologia pela Umesp (2013). Vice-coordenador da Faculdade de Direito da UFC e professor assistente da Universidade de Fortaleza. Atua nos seguintes temas: Filosofia do Direito, Hermenêutica jurídica, Teoria do Direito, Direitos Fundamentais e Imaginário Jurídico. Membro da Academia Cearense de Letras Jurídicas desde a sua fundação, ocupando a cadeira 28, tendo José de Alencar por patrono. Em 2012 recebeu o título de "Doutor Honoris Causa" e "Humanista Universal" do Sodima. http://lattes.cnpq.br/4306521902540146. https://orcid.org/0000-0001-5233-6807. glaucobarreira@yahoo.com.br
\end{abstract}

RESUMO

Trata-se de artigo científico que objetiva discutir soluções propostas por Boaventura de Sousa Santos e Joaquín Herrera Flores quanto ao confronto entre o universalismo e o relativismo como cosmovisões de direitos humanos. Para tanto, recorre-se à análise bibliográfica qualitativa. Inicialmente, perquiriu-se a definição de cosmovisões, a fim de inserir o universalismo e o relativismo como cosmovisões opostas, delineadas suas características fundamentais. Após, analisa-se a insuficiência das cosmovisões clássicas a partir de críticas propostas pela doutrina, inclusive as formuladas pelos dois autores especificamente estudados. Em seguida, discute-se o multiculturalismo como uma nova cosmovisão, buscando traçar seus significados possíveis, e, adotando-se a perspectiva do multiculturalismo progressista ou emancipatório, investiga-se mais a fundo as teorias de Santos e Herrera Flores, visando a estabelecer diferenças e semelhanças entre elas. Por fim, as considerações finais concluem que o multiculturalismo progressista ou interculturalismo é, de fato, uma cosmovisão apta a solucionar o embate entre as cosmovisões clássicas do universalismo e do relativismo.

Palavras-chave: Cosmovisões. Direitos humanos. Multiculturalismo. Interculturalismo.

HUMAN RIGHTS' CONFLICTS' WORLDVIEWS: UNIVERSALISM VERSUS RELATIVISM AND THE POSSIBLE MULTICULTURALISTIC SOLUTIONS BY BOAVENTURA DE SOUSA SANTOS AND JOAQUÍN HERRERA FLORES

\section{ABSTRACT}

This article aims to study Boaventura de Sousa Santos's and Joaquín Herrera Flores possible solutions for the confront between universalism and relativism towards the human rights vision. In the methodology, the bibliographical analyses will be employed. Firstly, the definition of worldview was searched, getting universalism and relativism doctrines apart, pointing their fundamental caractherisctics. In addition, it was exposed the classical worldviews' insufficiency, by showing the common critiques that they receive, including critics made by the two authors studied. Further, the multiculturalism was stated as a new worldview, searching its possible meanings and adopting the progressive or emancipatory multiculturalism perspective, going deeper into Santos and Herrera Flores' theories, aiming to stablish the differences and similitudes between them. Finally, the final considerations inquire if the multiculturalism or the interculturalism is, in fact, a worldview which is capable of solving the classical conflict between universalism and relativism.

Keywords: Worldviews. Human rights. Multiculturalism. Interculturalism.

1 Introdução. 2 Cosmovisões. 3 Cosmovisões em conflito: universalismo e relativismo dos direitos humanos. 3.1 Cosmovisão universalista. 3.2 Cosmovisão relativista. 3.3 Críticas às cosmovisões clássicas. 4 Multiculturalismo: uma nova cosmovisão? 4.1 Propostas conciliatórias multiculturalistas. 4.1.1 Boaventura de Sousa Santos e a hermenêutica diatópica. 4.1.2 Herrera Flores e o diálogo intercultural. 5 Semelhanças e diferenças entre as teorias de Boaventura de Sousa Santos e Joaquín Herrera Flores. 6 Considerações finais. 7 Referências. 


\section{Humanos \\ Democracia}

\section{INTRODUÇÃO}

O trabalho busca investigar a teoria dos direitos humanos, analisando o embate entre as correntes do universalismo e do relativismo como cosmovisões distintas, e, a partir de uma análise comparada, aprofundar as teorias críticas de direitos humanos formuladas por Boaventura de Sousa Santos e Joaquín Herrera Flores, que visam a construir, a partir de um diálogo intercultural, uma resposta a um dos maiores desafios da atualidade: a fundamentação dos direitos humanos.

A importância do estudo mostra-se, sobretudo, ao considerar-se o fato de que não há muitos trabalhos acadêmicos ${ }^{1}$ abordando as teorias de Santos e Herrera Flores de forma conjunta, apesar da conhecida convergência entre elas. Há, de fato, inúmeros trabalhos sobre ambos os autores separadamente. O âmbito acadêmico carece, todavia, de estudos que comparem as ideias dos dois, tratando de suas semelhanças e diferenças, o que justifica a relevância do presente trabalho.

Trata-se de tema de clara atualidade, na medida em que, "por força da crescente transumância e da globalização das relações humanas, avolumam-se os conflitos interculturais" (ZAGREBELSKY, 2011, p. 11), inclusive para análise do Judiciário, que deve estar apto a fornecer respostas adequadas, ${ }^{2}$ para as quais pretende este estudo contribuir.

Sob a perspectiva constitucional, ressalta-se a possível contribuição da pesquisa para ajudar com a construção de requisitos para a aprovação de tratados internacionais sobre matérias de direitos humanos com status de emendas constitucionais, com quórum especial, ${ }^{3}$ possuindo aplicabilidade prática.

Para além da relevância acadêmica, portanto, há também uma preocupação em contribuir com a problemática social, sobretudo no atual contexto de globalização (ou globalizações), ${ }^{4}$ em que as tensões entre as diferentes culturas exaltam-se. Afinal, o conhecimento jurídico não pode ficar reduzido ao papel de regulador de conflitos, mas deve possuir também um papel transformador do real, e contribuir com a emancipação da condição humana.

\footnotetext{
Usando a busca de teses no sistema Capes, existem apenas três trabalhos específicos sobre Herrera Flores e sete sobre Santos, porém nenhum tratando dos dois conjuntamente, o que demonstra ser um campo fértil à pesquisa aprofundada e comparada.

2 A título de exemplo, citam-se casos difíceis como o do "Crucifixo" e o do "Véu Islâmico", com os quais se defrontou o Tribunal Constitucional da Alemanha. Dentre outros casos polêmicos trazidos pelo contexto multi ou intercultural, citam-se também os seguintes exemplos: "Pode um motociclista sikh exigir que se lhe dispense da obrigação geral de usar capacete, invocando o seu dever religioso de vestir turbante? [...] Podem os pais recusar, por motivos religiosos, que receba transfusão de sangue um filho sem que esteja em perigo de morte? [...] Deve-se autorizar a poligamia aos imigrantes no país de acolhida quando ela é permitida em seu país de origem?" (ZAGREBELSKY, 2011, p. 12-13).

3 Constituição Federal de 1988: "Art. 5ㅇ, § 3o Os tratados e convenções internacionais sobre direitos humanos que forem aprovados, em cada Casa do Congresso Nacional, em dois turnos, por três quintos dos votos dos respectivos membros, serão equivalentes às emendas constitucionais".

4 "Para os meus objetivos analíticos privilegio uma definição de globalização mais sensível às dimensões sociais, políticas e culturais. Aquilo que habitualmente designamos por globalização são, de fato, conjuntos diferenciados de relações sociais; diferentes conjuntos de relações sociais dão origem a diferentes fenômenos de globalização. Nestes termos, não existe estritamente uma entidade única chamada globalização; existem, em vez disso, globalizações; em rigor, este termo só deveria ser usado no plural." (SANTOS, 2003b, p. 433).
} 
Preliminarmente, será introduzido brevemente o tema do Imaginário Jurídico, que busca ampliar nossas percepções quanto à maneira com que encaramos e nos relacionamos com o mundo e como isso reflete em nossa visão jurídica, por meio do conceito de cosmovisões. Após, serão analisadas as cosmovisões de direitos humanos conflituosas atualmente - o universalismo e o relativismo - para, depois, analisar-se se o multiculturalismo pode ser considerado uma nova cosmovisão, e, em seguida, investigar-se-ão propostas conciliatórias multiculturalistas, buscando comparar as diferenças e semelhanças entre as teorias críticas de Boaventura de Sousa Santos e Joaquín Herrera Flores, seguido das considerações finais.

Quanto à metodologia, será realizada a análise bibliográfica por meio da leitura de livros e trabalhos acadêmicos atinentes ao campo do Direito, Sociologia Jurídica e Imaginários. A pesquisa é do tipo bibliográfica e documental, com objetivos descritivo, explicativo e exploratório, com abordagem qualitativa.

\section{COSMOVISÕES}

Dentro do tema dos Imaginários - que tentam estabelecer a correlação entre o quadro de representações partilhadas e a vida social (LEGROS et al., 2007, p. 28), utilizando o simbólico, que é o componente de todo imaginário (CASTORIADIS, 2000, p. 154) - é importante a definição de cosmovisões, ${ }^{5}$ que podem ser concebidas como esquemas de pensamento e ação dentro dos quais as pessoas operam, ou conjuntos de "pressuposições (hipóteses que podem ser verdadeiras, parcialmente verdadeiras ou inteiramente falsas) que sustentamos (consciente ou inconscientemente, consistente ou inconsistentemente) sobre a formação básica do nosso mundo" (SIRE, 2001, p. 20-21).

James W. Sire (2001, p. 22) ressalta que nem sempre pensamos sobre as cosmovisões, que são apenas lembradas quando somos desafiados por um "estrangeiro de outro universo ideológico": é exatamente o que ocorre entre os que pensam os direitos humanos de forma universalista e os que pensam de forma relativista, enquadrando-se em verdadeiras cosmovisões opostas, conflituosas. Para aquele que está inserido em uma cosmovisão, as respostas são tão óbvias que sequer merecem consideração, sem qualquer ideia de que muitos outros não a compartilham, ignorando a perspectiva de um mundo pluralista. Boaventura de Sousa Santos ressalta que isso ocorre com a ideia (ou cosmovisão, como ora trabalhado) universalista de direitos humanos que, por ser tão arraigada, nem percebemos que existem outras alternativas possíveis.

Assim, pensar em termos de cosmovisões é pensar com "consciência não apenas do nosso modo de pensar, mas também do modo de pensar das outras pessoas, para que possamos primeiro entender os outros e, então, estabelecer uma comunicação eficaz em nossa sociedade pluralista" (SIRE, 2001, p. 19). Para este objetivo se estendem as visões que pensam

\footnotetext{
É importante também o conceito de "imaginário", mas, pelas delimitações do estudo, o foco será nas cosmovisões, porém "é através do imaginário que atribuímos sentido às coisas e as religamos numa rede significativa chamada de cosmovisão" (MAGALHÃES FILHO, 2012, p. 02). Ainda: "A pessoa se religa ao mundo por meio da rede de sentidos que constitui sua identidade. É assim como transformar o caos das impressões num cosmo de sentidos. Ela configura o mundo natural dado como um cosmo de sentidos criados, uma cosmovisão" (RUIZ, 2003, p. 56).
} 


\section{Humanos e \\ Democracia}

os direitos humanos de forma conciliatória, analisadas neste estudo, que buscam ir além das cosmovisões clássicas, universalista e relativista, cada uma extremada a seu modo, procurando uma solução que leve em conta o pluralismo, o multiculturalismo ou o interculturalismo.

Afinal, como já dizia Sócrates na Antiguidade Grega, é preferível viver uma vida refletida, ${ }^{6}$ plenamente consciente das cosmovisões existentes e de seus conflitos, sendo o objetivo do presente artigo a procura de alternativas e soluções dentro da perspectiva do Imaginário Jurídico, o qual busca ampliar nossas percepções de como encaramos e nos relacionamos com o mundo, e como isso reflete em nossa visão jurídica.

\section{COSMOVISÕES EM CONFLITO: UNIVERSALISMO E RELATIVISMO DOS DIREITOS HUMANOS}

A teoria clássica dos direitos humanos - ou cosmovisões clássicas dos direitos humanos, na perspectiva adotada neste estudo - divide-se em universalismo e relativismo. Primeiramente, serão ambas analisadas separadamente de forma breve - pois o foco maior do artigo será a cosmovisão multiculturalista, que vai além do dualismo inicialmente pensado - e, depois, será demonstrada a insuficiência de as cosmovisões clássicas fundamentarem os direitos humanos devidamente, sob a ótica multi ou intercultural de relações globalizadas nas quais vivemos atualmente.

É importante ressaltar que o debate entre os universalistas e os relativistas retoma a discussão sobre o alcance das normas de direitos humanos: "podem elas ter um sentido universal ou são culturalmente relativas?" Segundo Piovesan (2007, p. 142),

Essa disputa alcança novo vigor em face do movimento internacional dos direitos humanos, na medida em que tal movimento flexibiliza as noções de soberania nacional e jurisdição doméstica, ao consagrar um parâmetro internacional mínimo, relativo à proteção dos direitos humanos, aos quais os Estados devem se conformar.

Ainda, é essencial a busca da fundamentação dos direitos humanos em razão da necessidade de seu mais amplo reconhecimento - como já dizia Bobbio (1992, p. 16) - e, indo além, de sua efetivação.

\subsection{Cosmovisão universalista}

Com a internacionalização dos direitos humanos, após as atrocidades cometidas na Segunda Guerra Mundial, surgiu a Declaração Universal dos Direitos Humanos (DUDH) de 1948, que adotou expressamente o universalismo ao prever que todos os direitos ali elencados devem ser respeitados pela totalidade dos Estados-parte das Nações Unidas. Desde então esta opção perpetuou-se, a exemplo da Declaração de Viena de 1993 (parágrafo 5o do item I). ${ }^{7}$ Acerca da força normativa, ressalta-se que a DUDH não é um tratado, mas uma resolução, e, em relação ao quórum, a citada Declaração foi adotada em um foro então composto por apenas 56 países, à medida que a Declaração de Viena de 1993 envolveu 171 Estados. Por isso,

\footnotetext{
Ou, como dito por Sire (2001, p. 23): "A hipótese deste livro é que uma vida examinada é melhor".

"Todos os direitos humanos são universais, indivisíveis, interdependentes e inter-relacionados. A comunidade internacional deve tratar os direitos humanos globalmente de forma justa e equânime, com os mesmos parâmetros e com a mesma ênfase".
} 
parte da doutrina ${ }^{8}$ entende que a Declaração de Viena conferiu caráter efetivamente universal àquela primeira declaração de 1948. Os instrumentos internacionais de direitos humanos, portanto, acolheram o "forte universalismo". 9

Para os que compartilham a cosmovisão universalista, o fundamento dos direitos humanos é a dignidade humana como valor intrínseco à própria condição humana, de forma que qualquer afronta ao chamado "mínimo ético irredutível", mesmo que em nome da cultura, importará em violação a direitos humanos (PIOVESAN, 2007, p. 144). Acredita-se, desta feita, que a condição de pessoa é o requisito único para a titularidade de direitos humanos.

Foram criados "princípios universais válidos independentes de contexto, ainda que sempre favoráveis aos contextos em que pode florescer o projeto moderno capitalista ocidental e cristão" (SANTOS, 2007, p. 29). Todos os costumes e culturas que não se encaixassem neste padrão eram tratados como inferiores, como no colonialismo, em que muitos "foram forçados a abandonar os princípios que os tinham guiado antes de chegarem à zona de contato, outros adaptaram voluntariamente os novos princípios. A força dos novos princípios foi quase sempre a força de quem os podia impor" (SANTOS, 2007, p. 29). Nesse diapasão, os países que adotavam os direitos humanos sob a perspectiva dita universalista foram considerados avançados, progressistas, desenvolvidos, enquanto todos os demais foram desclassificados como residuais, atrasados e primitivos. ${ }^{10}$

Segundo Boaventura de Sousa Santos (2007, p. 33-36), o modo como essas ideias universalistas foram impostas foi autoritário e sempre a serviço de um projeto de dominação econômica, política, social e cultural, em que a conversão toma prioridade em relação à conversação. ${ }^{11}$ Assim, os direitos humanos, ao serem transportados de uma cultura imperialista para países periféricos, tomaram o caráter de "corpo estranho quando implantado", pois não se coadunavam com a cultura local, o que causava uma sensação de estranheza, e não de pertencimento. Nesta toada, a cosmovisão universalista induziria à destruição da diversidade cultural. Conclui Santos, entretanto, que, historicamente, os direitos humanos foram estabelecidos "em contextos imperiais, coloniais e neocoloniais e, portanto, no seio de relações de poder extremamente desiguais". ${ }^{12}$

[...] qual o critério de verdade que legitima a imposição de crenças particulares à obediência geral, como acontece na seara dos direitos humanos, cujas declarações, embora autodenominadas universais, são vistas pelos seus críticos como texto simplesmente ocidentais e, por isso mesmo, carentes de normatividade para quem vive do outro lado do mundo e ali se conduz em conformidade com valores diversos (COELHO, 2011, p. 11).

\footnotetext{
Como Lindgren Alves (1994, p. 105).

Como defendido por Donnelly (1989, p. 109). A título de exemplo, os instrumentos internacionais citados usam expressões como "todas as pessoas" (artigo 2o da DUDH), "ninguém" (artigo 5o da DUDH: "ninguém poderá ser submetido à tortura"), dentre outras.

${ }^{10}$ Desta forma, "[...] a monocultura do universalismo, consistiu e atribuiu prioridade cognitiva e ética a entidades consideradas válidas, independentemente dos contextos. A identificação dessas entidades (princípios, valores) ficou a cargo daqueles com poder para transformar os seus contextos de atuação e interesse em situações ideais e gerais" (SANTOS, 2007, p. 29).

11 “O global e universal é hegemônico; o particular e local não conta, é invisível, descartável, desprezível." (SANTOS, 2007, p. 31).

${ }^{12}$ Eis o desafio de se criar uma "epistemologia do Sul superadora da matriz colonizadora" (SANTOS, 2007, p. 10).
} 


\section{Humanos e \\ Democracia}

Em outras palavras, por que os direitos humanos sob a perspectiva da cosmovisão ocidental deveriam ser legitimamente trasladados para a cosmovisão oriental, mesmo se tratando de cosmovisões tão distintas? Essa principal crítica ensejou o surgimento de uma cosmovisão contrária à universalista: a relativista, que busca fundamentar as culturas em cada contexto no qual se encontram.

\subsection{Cosmovisão relativista}

Na cosmovisão relativista, a noção de direito está intrinsecamente ligada ao sistema político, econômico, cultural, social e moral vigente em determinada cultura ou sociedade, de forma que cada uma delas possui seu próprio discurso a respeito dos direitos humanos, que se relaciona com suas específicas circunstâncias culturais e históricas. Por conseguinte, "o pluralismo cultural impede a formação de uma moral universal, tornando-se necessário que se respeitem as diferenças culturais apresentadas por cada sociedade, bem como seu peculiar sistema moral" (PIOVESAN, 2007, p. 147). Assim,

Não há moral universal, já que a história do mundo é a história de uma pluralidade de culturas e, neste sentido, buscar uma universalidade, ou até mesmo o princípio da universalidade clamado por Kant, como critério para toda moralidade, é uma versão imperialista de tentar fazer com que valores de uma determinada cultura sejam gerais (VINCENT, 1986, p. 37-38).

Segundo Bobbio, "o que parece fundamental numa época histórica e numa determinada civilização não é fundamental em outras épocas e em outras culturas" (BOBBIO, 1992, p. 18-19). Sendo assim, o autor não concebe a possibilidade de um fundamento absoluto e universal a direitos que são historicamente relativos. ${ }^{13}$

Há, ainda, corrente, como a de Jack Donnelly (1989, p. 109-110), que diferencia o forte relativismo cultural - para o qual a cultura é a principal fonte de validade de um direito ou regra moral - e o fraco relativismo cultural - segundo o qual a cultura pode ser uma importante fonte de validade de um direito ou regra moral.

Outro argumento usado por aqueles que defendem a cosmovisão relativista é de que, à época da Declaração Universal dos Direitos Humanos, em 1948, sua adoção foi resolvida por um foro de apenas 56 países, e que grande parte dos países africanos e asiáticos eram ainda colônias de países imperialistas que impuseram sua cosmovisão.

A principal crítica feita à cosmovisão relativista, todavia, é que ela pode acabar permitindo práticas condenáveis, revelando "o esforço de justificar graves casos de violações dos direitos humanos que, com base no sofisticado argumento do relativismo cultural, ficariam imunes ao controle da comunidade internacional" (PIOVESAN, 2007, p. 145). Neste sentido,

\footnotetext{
${ }^{3}$ É importante destacar que, embora pareça que Bobbio defenda a cosmovisão relativista, ele aceita a existência de uma universalidade espacial de direitos humanos, isto é, que deriva de um consenso obtido entre diversos povos em um determinado momento histórico.
} 
Nós não podemos passivamente assistir a atos de tortura, desaparecimentos, detenção e prisão arbitrária, racismo, anti-semitismo, repressão a sindicatos e Igrejas, miséria, analfabetismo e doenças em nome da diversidade ou respeito a tradições culturais. Nenhuma dessas práticas merece nosso respeito, ainda que seja considerada uma tradição (DONNELLY, 1989, p. 235). ${ }^{14}$

A seguir, as críticas às cosmovisões clássicas, em conjunto, serão aprofundadas, com destaque para as formuladas pelos dois autores enfocados no presente trabalho: Boaventura de Sousa Santos e Joaquín Herrera Flores.

\subsection{Críticas às cosmovisões clássicas}

Na perspectiva da teoria crítica dos direitos humanos e multiculturalismo, nos últimos anos do século 20 e início do 21 tem-se observado uma insuficiência da teoria clássica dos direitos humanos em, sob a perspectiva restrita do universalismo e do relativismo, fundamentá-los a contento ante uma sociedade globalizada. Desta maneira, perante o desafio do pluralismo multicultural, passa-se a analisar as críticas formuladas por Boaventura de Sousa Santos e Joaquín Herrera Flores à teoria clássica dos direitos humanos, entendidas, neste estudo, como cosmovisões clássicas (universalismo e relativismo). Preliminarmente, no entanto, é necessário expor, de forma breve, a definição de direitos humanos estabelecida pelos autores ora estudados.

Segundo Herrera Flores (2009a, p. 49), os direitos humanos são produtos culturais, constituindo uma maneira de enxergar o outro de modo diverso, ou seja, "não mais como o bárbaro, como o incivilizado e, consequentemente, passível de colonizar, mas, sim, simplesmente como o diferente", ou, ainda, como aquele que, "no decorrer da própria história, procurou caminhos diferentes para buscar os elementos que considera essenciais para atingir as próprias concepções de dignidade humana" (COPELLI, 2014, p. 10).

Para Santos e Herrera Flores, o conceito de direitos humanos difundido é precipuamente ocidental, e, como adotado neste estudo, norte-ocidental, ou seja, imposto por países hegemônicos do Ocidente, como os Estados Unidos e os países europeus mais industrializados, e não dos que sofreram o processo de colonização, a exemplo dos latino-americanos. Nesse sentido, consoante Santos, os direitos humanos "pretendem ser uma resposta forte para os problemas do mundo, tão forte que se pretende universalmente válida" (SANTOS, 2007, p. 24). Dentro de um contexto de injustiça social, "os direitos humanos apresentam-se como resposta fraca, não suficiente, em razão das desigualdades e discriminações, que não são consideradas no discurso e nas práticas de direitos humanos" (SANTOS, 2007, p. 24). Para ele, a fragilidade dos direitos humanos decorre também do chamado "cemitério de promessas traídas". ${ }^{15}$

\footnotetext{
${ }^{14}$ Indo além, em forte crítica, Kersting (2003, p. 87) assevera que aqueles que defendem a cosmovisão relativista tornam-se "idiotas úteis dos ditadores deste mundo que, a pretexto de autodefesa cultural, isolam seus regimes autocráticos contra a penetração de exigências de democracia e Estado de direito".

15 "As promessas da modernidade - a liberdade, a igualdade e a solidariedade - continuam sendo uma aspiração para a população mundial" (SANTOS, 2007, p. 19).
} 


\section{Humanos e \\ Democracia}

Não se deve, com isso, porém, excluir a importância dos direitos humanos, e sim reformulá-los para um contexto pós-colonial, a fim de que eles adquiram uma carga axiológica multicultural, adaptando-os para um contexto de globalização anti-hegemônica a serviço de uma política progressista e emancipatória. É neste sentido, defendido por Boaventura de Sousa Santos e Joaquín Herrera Flores, respectivamente citados - e com pensamentos convergentes - que o presente trabalho se alinha:

Isto não significa que devam ser descartados. Pelo contrário, nunca como hoje foi importante não desperdiçar ideias e práticas de resistência. Significa apenas que só reconhecendo as debilidades atuais dos direitos humanos é possível construir a partir deles, mas para além deles, ideias e práticas de resistência fortes (SANTOS, 2007, p. 37).

Não podemos analisar os direitos humanos de fora de seus contextos ocidentais. Porém, também não devemos esquecer sua enorme capacidade de gerar esperanças na luta contra as injustiças e explorações que sofre grande parte da humanidade. São essas lutas que, na realidade, permitem que tal conceito se 'universalize' como base ética e jurídica de toda prática social voltada a criar e garantir instrumentos úteis na hora de poder ascender aos bens materiais e imateriais exigíveis para se viver com dignidade (FLORES, 2009a, p. 42-43).

Para os que compartilham a cosmovisão universalista, como já explicado, o fundamento dos direitos humanos está intimamente relacionado à dignidade humana e o mínimo ético irredutível. Segundo Santos, universalismo é, sucintamente, toda ideia ou entidade que é válida independentemente do contexto no qual ocorre, conceito tão difundido que quando começamos a ter um conhecimento da prática global, da globalização alternativa, é que nos damos conta de que aquilo que antes acreditávamos ser universal de fato é local, ocidental (SANTOS, 2009, p. 59). Ou seja, trata-se de uma cosmovisão dominante.

Os direitos humanos não são universais na sua aplicação. Na atualidade são consensualmente identificados quatro regimes internacionais de aplicação de direitos humanos: o europeu, o interamericano, o africano e o asiático. Percebe-se que todas as culturas tendem a considerar os seus valores máximos como os mais abrangentes, contudo apenas a cultura ocidental tende a formulá-los como universais (SANTOS, 2003b, p. 438-439).

Em oposição ao pretenso universalismo dos direitos humanos, ganhou importância a perspectiva relativista (que, pela crítica universalista, não passa de uma desculpa para violar direitos humanos), ${ }^{16}$ a qual defende que a noção de direitos humanos está estritamente relacionada ao sistema político, econômico, cultural, social e moral vigente em determinada sociedade, não havendo moral universal, como já exposto.

Nenhuma das duas cosmovisões clássicas, entretanto, mostrou-se suficiente para fundamentar os direitos humanos no contexto atual. Santos e Herrera Flores, respectivamente, criticam o universalismo e o relativismo:

\footnotetext{
16 "Sustentar que quaisquer práticas seriam legítimas desde que compartilhadas por uma comunidade é, a maioria das vezes, um discurso extremamente autoritário, capaz de encobrir desigualdades, reprimir a liberdade e legitimar a dominação" (COPELLI, 2014, p. 15).
} 
[...] a superação do debate sobre universalismo e relativismo cultural. Trata-se de um debate intrinsecamente falso, cujos conceitos polares são igualmente prejudiciais para uma concepção emancipatória de direitos humanos. Todas as culturas são relativas, mas o relativismo cultural enquanto atitude filosófica é incorreto. Todas as culturas aspiram a preocupações e valores universais, mas o universalismo cultural, enquanto atitude filosófica, é incorreto. Contra o universalismo, há que propor diálogos interculturais sobre preocupações isomórficas, isto é, preocupações convergentes ainda que expressas em linguagens distintas e a partir de universos culturais diferentes. Contra o relativismo, há que desenvolver critérios políticos para distinguir política progressista de política conservadora de direitos humanos (SANTOS, 2003b, p. 441).

A polêmica sobre os direitos humanos, no mundo contemporâneo, centra-se, atualmente, em duas visões, duas racionalidades e duas práticas. Em primeiro lugar, uma visão abstrata, vazia de conteúdo, referenciada nas circunstâncias reais das pessoas e centrada na concepção ocidental de direito e do valor da identidade. E, em segundo lugar, uma visão localista, na qual predomina o "próprio", o nosso, com respeito ao dos outros, e centrada na ideia particular de cultura e de valor da diferença (FLORES, 2009 , p. 155).

Mediante a análise de seus pressupostos básicos, tanto o universalismo quanto o relativismo mostram-se insuficientes para fundamentar os direitos humanos ante o contexto atual, em que extremismos são prejudiciais. Há, portanto, problemas em ambas as cosmovisões clássicas, como afirma Herrera Flores (2009 , p. 156): “o problema surge quando cada uma dessas visões passa a ser defendida apenas por seu lado, e tende a considerar inferior as demais, desdenhando outras propostas".

Verifica-se que a cosmovisão universalista acabou impondo direitos humanos sob a perspectiva ocidental ao resto do mundo, em um contexto hegemônico pós-colonial. Por outro lado, a cosmovisão relativista torna os países fechados em si mesmos, refratários em estabelecer diálogo com outras culturas. Assim, é necessário pensar os direitos humanos a partir de um novo viés, que enxergue além das cosmovisões tradicionais: o multiculturalismo.

\section{MULTICULTURALISMO: UMA NOVA COSMOVISÃO?}

Estudadas as cosmovisões clássicas (universalista e relativista), antecedentes do multiculturalismo, passa-se a analisar o multiculturalismo como teoria crítica e nova perspectiva, investigando a hipótese de ele ser uma nova cosmovisão.

O conceito atual de multiculturalismo ${ }^{17}$ diz respeito ao modo de descrever as diferenças culturais num contexto transnacional e global. Boaventura de Sousa Santos, porém, alerta que existem diferentes noções de multiculturalismo, nem todas de sentido emancipatório, sendo essas as que se baseiam no "reconhecimento da diferença e do direito à diferença e da coexistência ou construção de uma vida comum além de diferenças de vários tipos" (COPELLI, 2014, p. 33).

\footnotetext{
$17 \mathrm{O}$ conceito de multiculturalismo [...] enquanto descrição, pode referir-se: 1 . à existência de uma multiplicidade de culturas no mundo; 2. à coexistência de culturas diversas no espaço de um mesmo Estado-nação; 3. à existência de culturas que se interinfluenciam tanto dentro como além do Estado-nação (SANTOS, 2003b. p. 28).
} 


\section{Humanos e \\ Democracia}

Destarte, o multiculturalismo mostra-se como uma nova cosmovisão ampla, podendo ser vista sob, no mínimo, quatro enfoques, segundo diferenciação clássica de McLaren (1997, p. 311): o multiculturalismo conservador, o humanista liberal, o liberal de esquerda e o crítico/de resistência/revolucionário. Embora as limitações verticais deste artigo não permitam o aprofundamento das diferentes vertentes multiculturalistas, mostra-se relevante ressaltar que as teorias que são discutidas, de Santos e Hererra Flores, encaixam-se nos multiculturalismos progressistas. Conforme Joaquín Herrera Flores, as visões tradicionais do multiculturalismo não acrescentam muito aos problemas concretos que enfrentamos hoje em dia, pois, se por um lado temos as propostas multiculturalistas de tendência conservadora e que compartem um ponto de vista universalista abstrato, "que, como tal, não pode ser questionado, apesar das enormes falhas e das consequências desastrosas que estão provocando para a maioria da humanidade" (FLORES, 2009c, p. 154-155), de outro existem as posições multiculturalistas holistas, nativistas ou localistas, que "tampouco acrescentam a nosso debate, dado o radicalismo na esfera das raízes identitárias ou dos parâmetros religiosos totalizados" (FLORES, 2009c, p. 154-155). Desta forma, ambas dificultam ainda mais a exigência cultural do diálogo e a prática social intercultural.

Uma outra delimitação semântica deve ser feita, tendo em vista a existência de autores $^{18}$ que estabelecem uma diferenciação entre multiculturalismo/multiculturalidade e interculturalismo/interculturalidade:

O mais apropriado é utilizar o termo multiculturalismo para a constatação empírica da coexistência das culturas, enquanto que o interculturalismo tem uma pretensão normativa ou prescritiva e diz respeito à exigência de um tratamento igualitário dispensável às culturas. $\mathrm{O}$ interculturalismo atua em conformidade com os conceitos garantistas dos direitos das culturas, criticando o imperialismo jurídico e propondo uma alternativa entre o liberalismo e o comunitarismo (SORIANO, 2004, p. 91).

A interculturalidade, diferentemente da multiculturalidade, não é simplesmente duas culturas que se mesclam ou que se integram. A interculturalidade alude a um tipo de sociedade em que as comunidades étnicas, os grupos sociais se reconhecem em suas diferenças e buscam uma mútua compreensão e valorização. O prefixo "inter" expressaria uma interação positiva que concretamente se expressa na busca da supressão das barreiras entre os povos, as comunidades étnicas e os grupos humanos (ASTRAIN, 2003, p. 327).

A interculturalidade não se confunde com o multiculturalismo, pois este se refere à síndrome ocidental que consiste em acreditar que existe uma supercultura, superior a todas, capaz de oferecer uma benigna e condescendente hospitalidade e dar uma resposta aos problemas supostamente universais. [...] Já a interculturalidade pergunta-se sobre quais são estes problemas presumidamente universais. Caracteriza-se pela exigência de abertura ao outro (PANIKKAR apud VALLESCAR PALANCA, 2000, p. 266).

${ }^{18}$ Citam-se, dentre outros: Astrain, Fornet-Betancourt, Soriano e Pannikar. 
Este estudo defende, no entanto, que as linhas de Boaventura de Sousa Santos e Joaquín Herrera Flores não se encaixam nessa diferenciação estabelecida pela citada corrente doutrinária por não serem divergentes, e sim convergentes: o multiculturalismo do primeiro é o emancipatório, e o do segundo é o crítico ou de resistência, e, conforme será analisado mais profundamente no próximo tópico, o multiculturalismo de ambos respeita as diferenças. Inclusive, Santos ressalta a importância do respeito à igualdade conjugada com o princípio do reconhecimento da diferença. ${ }^{19}$ Pode-se, portanto, afirmar que o multiculturalismo de Santos - por encaixar-se no viés emancipatório ${ }^{20}$ deste termo - é semelhante ao interculturalismo de Herrera Flores.

Nessa esteira, o multiculturalismo vai além das cosmovisões clássicas, levando-se em conta a insuficiência dessas em fundamentar os direitos humanos sob o contexto contemporâneo. Ainda, pode ser considerado uma nova cosmovisão, pois propõe um novo esquema de pensamento e ação dentro do qual as pessoas operam, buscando reconhecer e respeitar a diferença em um mundo de pluralidades. Mesmo na diferença, portanto, há de se encontrar denominadores comuns (LACERDA, 2010, p. 42).

Sendo o multiculturalismo um termo com múltiplos sentidos, todavia, ressalta-se que, como cosmovisão trabalhada no presente estudo, adota-se seu sentido emancipatório ou progressista, sendo convergente ao interculturalismo.

Feitas as delimitações semânticas, passa-se a analisar as propostas conciliatórias propriamente ditas, que buscam ir além do conflito entre as cosmovisões universalista e relativista de direitos humanos. Ressalta-se que a convergência entre as teorias críticas ora analisadas - ou cosmovisões, no viés ora proposto - pode levar a certas confusões semânticas em razão do uso de termos semelhantes. Por isso, torna-se premente uma investigação profunda nos trabalhos de Boaventura de Sousa Santos e Joaquín Herrera Flores, que são essenciais para uma nova fundamentação dos direitos humanos.

\subsection{Propostas conciliatórias multiculturalistas}

A pergunta condutora deste tópico será: Quais teorias mostram-se aptas a resolver um dos grandes desafios da atualidade e compatibilizar o respeito às particularidades de cada cultura com a busca por uma maior aceitação pela sociedade?

\footnotetext{
${ }^{19}$ Neste sentido: "necessitamos construir a emancipação a partir de uma nova relação entre o respeito da igualdade e o princípio do reconhecimento da diferença. Na modernidade ocidental, até agora não tratamos isso de maneira adequada, porque - sobretudo na teoria crítica - toda a energia emancipatória teórica foi orientada pelo princípio da igualdade, não pelo princípio do reconhecimento das diferenças. Agora temos de tentar uma construção teórica em que as duas estejam presentes, e saber que uma luta pela igualdade tem de ser também uma luta pelo reconhecimento da diferença, porque o importante não é a homogeneização, mas as diferenças iguais" (SANTOS, 2007, p. 62-63). "O multiculturalismo progressista pressupõe que o princípio da igualdade seja utilizado de par com o princípio do reconhecimento da diferença. A hermenêutica diatópica pressupõe a aceitação do seguinte imperativo transcultural: temos o direito de ser iguais quando a diferença nos inferioriza e a ser diferentes quando a igualdade nos descaracteriza" (SANTOS, 2003b, p. 458).

${ }^{20}$ Com relação às formas progressistas e inovadoras, Santos destaca o multiculturalismo emancipatório, ou seja, um multiculturalismo pós-colonial. A política da diferença "é o que ele tem de novo em relação às lutas da modernidade ocidental do século 20, lutas progressistas, operárias e outras que assentaram muito no princípio da igualdade" (2003a, p. 12).
} 


\section{Humanos e \\ Democracia}

Dentre tantas teorias críticas que visam a fundamentar os direitos humanos sob uma perspectiva conciliatória, em razão do limite da pesquisa será feito um enfoque nas teorias de Boaventura de Sousa Santos (multiculturalismo contra-hegemônico ou cosmopolita) e Joaquín Herrera Flores (universalismo de confluência), por serem mais bem aplicadas ao contexto latino-americano dentro do qual o Brasil se insere.

A rigor, não se desconhece que existem outras teorias aptas a compatibilizar as cosmovisões clássicas, como o universalismo pluralista de Bhirku Parekh, o enfoque asiático feito por Amartya Sen e as reflexões de Abdullah Ahmed An-na'im sobre os direitos humanos no mundo islâmico, ou a proposta de Wolfgang Kersting (2003, p. 82-83) de buscar uma instância pré-cultural, de fundamento antropológico. Há, ainda, no âmbito nacional, a teoria do duplo dialogo de André de Carvalho Ramos. Em razão de recorte metodológico, contudo, essas não serão aprofundadas, pois o objeto é a análise de dois autores - Santos e Herrera Flores -, em virtude da maior similitude entre suas ideias e do recorte metodológico já explanado. Nestes termos, delimita-se o tema, buscando-se aprofundar as teorias dos dois autores citados e suas semelhanças e diferenças, investigando se tais diferenças permanecem após análise profunda.

Desta forma, adotando-se a posição de Boaventura de Sousa Santos de globalizações hegemônica e contra-hegemônica, vê-se que, estando o Brasil inserido em um contexto de desenvolvimento em andamento e sofrendo constantes imperialismos culturais, procuram-se teorias multiculturalistas que abordem com mais proficiência essa tensão Norte versus Sul. Embora alguns autores abordem também o conflito Ocidente versus Oriente, ${ }^{21}$ essa concepção não se mostra aplicável ao contexto dos países latino-americanos, os quais, desde à época da colonização, ${ }^{22}$ mostram-se subjugados culturalmente às visões hegemônicas dos países capitalistas, os quais ditam o que são e o que não são direitos humanos, mesmo inseridos no lado ocidental do globo.

A cosmovisão multiculturalista, que vai além das cosmovisões clássicas (universalista e relativista), busca compatibilizar as cosmovisões de direitos humanos, respeitando-se as particularidades de cada cultura, porém sem reputar que estas são completas, nesse último ponto, diferindo, portanto, do relativismo. Como já afirmado alhures, neste sentido teoriza-se que o universalismo acabou por impor visões ocidentais (e, na linha de pesquisa que se adota, norte-ocidentais, ou seja, visões de países hegemônicos ocidentais, como os Estados Unidos e os países europeus, e não dos que sofreram o processo de colonização) ao resto do mundo, o que se denomina "imperialismo cultural" ou "canibalismo cultural". Buscam-se, desta forma, teorias (ou cosmovisões) que tenham como base o diálogo intercultural, sob a perspectiva multiculturalista.

\footnotetext{
${ }^{21}$ Como os já citados Bhirku Parekh (com o universalismo pluralista), Amartya Sen (e sua teoria com enfoque asiático) e Abdullah Ahmed An-na'im (sobre os direitos humanos no mundo islâmico).

${ }^{22}$ Santos conceitua colonialismo como a "a incapacidade de reconhecer o outro como igual, a objetivação do outro transformar o outro em objeto" (2007, p. 53.) Ainda: "Será que podemos dizer que o colonialismo passou, e que com poucas exceções só há países independentes? Não. Em nossas teorias temos de incluir a perspectiva pós-colonial, que tem duas ideias muito categóricas. A primeira é que terminou o colonialismo político, mas não o colonialismo social ou cultural (p. 59).
} 


\subsubsection{Boaventura de Sousa Santos e a hermenêutica diatópica}

Preliminarmente, é importante definir com brevidade os contornos do termo globalizações ${ }^{23}$ na teoria de Santos - por constituírem importante pressuposto para entender sua construção de uma teoria multiculturalista emancipatória. Faz-se a distinção entre globalização de-cima-para-baixo ou hegemônica e globalização de-baixo-para-cima ou contra-hegemônica: "O que eu denomino de localismo globalizado e globalismo localizado são globalizações de-cima-para-baixo, neoliberal ou hegemônica; cosmopolitismo e patrimônio comum da humanidade são globalizações de-baixo-para-cima, solidária ou contra-hegemônica" (SANTOS, 2003b, p. 438).

Defende Santos que o conceito de direitos humanos, como conhecemos, foi fruto de uma globalização hegemônica e, portanto, imposta; "enquanto forem concebidos como direitos humanos universais, os direitos humanos tenderão a operar como localismo globalizado - uma forma de globalização de-cima-para-baixo" (SANTOS, 2003b, p. 438), sendo sempre um instrumento do choque de civilizações, como arma do Ocidente contra o resto do mundo. Há, contudo, o lado oposto, que é a globalização anti-hegemônica, surgida por meio da luta de "milhões de pessoas e milhares de ONG's que lutam pelos direitos humanos, muitas vezes correndo grandes riscos, em defesa de classes sociais e grupos oprimidos, em muitos casos vitimizados por Estados capitalistas autoritários" (SANTOS, 2003b, p. 440-441), combatendo desigualdades, opressão e destruição dos modos de vida e do meio ambiente, causados ou agravados pela globalização hegemônica.

O autor propõe-se, portanto, a reconceitualizar os direitos humanos como multiculturais, para que estes possam operar de forma cosmopolita ${ }^{24}$ (aqui utilizado como um tipo de globalização de-baixo-para-cima ou contra-hegemônica), sob uma ótica progressista e emancipatória. Neste contexto, o multiculturalismo de Boaventura de Sousa Santos é o cosmopolita, destacando que é necessária a superação do debate entre universalistas e relativistas, pois a polarização de conceitos é prejudicial para uma concepção emancipatória dos direitos humanos.

A reconceitualização e a transformação dos direitos humanos devem ser feitas por intermédio de um processo hermenêutico diferenciado: a hermenêutica diatópica, que se fundamenta na ideia de que os topoi ${ }^{25}$ de uma cultura são tão incompletos quanto a própria cultura a que fazem parte. Essa incompletude, porém, não é percebível dentro dessa cultura, pois a pretensão à totalidade conduz a que se tome a parte pelo todo. Aplicando-se à dignida-

\footnotetext{
${ }^{23}$ Primeiramente, define globalização como "o processo pelo qual determinada condição ou entidade local estende a sua influência a todo o globo e, ao fazê-lo, desenvolve a capacidade de designar como local outra condição social ou entidade rival" (SANTOS, 2003b, p. 433). Após, adota o termo "globalizações" no plural ao invés de "globalização" no singular, ante os múltiplos conjuntos diferenciados de relações sociais, que dão origem a diferentes fenômenos de globalização, como o hegemônico e o contra-hegemônico.

24 "Não uso cosmopolitismo no sentido moderno convencional. Para mim, cosmopolitismo é a solidariedade transnacional entre grupos explorados, oprimidos ou excluídos pela globalização hegemônica. [...] O cosmopolitismo que defendo é o cosmopolitismo do subalterno em luta contra a sua subalternização" (SANTOS, 2003b, p. 436-437).

25 "Os topoi são lugares comuns retóricos mais abrangentes de determinada cultura. Funcionam como premissas de argumentação que, por não se discutirem, dada a sua evidência, tornam possível a produção e a troca de argumentos" (SANTOS, 2003b, p. 443)
} 


\section{Humanos e \\ Democracia}

de humana, por exemplo, percebe-se que todas as culturas possuem concepções diferentes que, todavia, são incompletas. Veja-se, nessa linha, um dos exemplos mais conhecidos de aplicação da hermenêutica diatópica de Santos (2003b):

Um exemplo de hermenêutica diatópica é a que pode ter lugar entre o topos dos direitos humanos na cultura ocidental, o topos do dharma na cultura hindu e o topos da umma na cultura islâmica. [...] Vistos a partir do topos do dharma, os direitos humanos são incompletos na medida em que não estabelecem a ligação entre a parte (o indivíduo) e o todo (o cosmos). Vista a partir do dharma, e na verdade também a partir da umma, a concepção ocidental dos direitos humanos está contaminada por uma simetria muito simplista e mecanicista entre direitos e deveres. Apenas garante direitos àqueles a quem pode exigir deveres. Isto explica por que razão, na concepção ocidental dos direitos humanos, a natureza não possui direitos: porque não the podem ser impostos deveres. [...] Por outro lado e inversamente, visto a partir do topos dos direitos humanos, o dharma também é incompleto, dado o seu enviezamento fortemente não-dialético a favor da harmonia, ocultando assim injustiças. Mas, por outro lado, a partir do topos dos direitos humanos individuais, a umma sublinha demasiado os deveres em detrimento dos direitos e por isso tende a perdoar desigualdades que seriam de outro modo inadmissíveis, como a desigualdade entre homens e mulheres ou entre muçulmanos e não-muçulmanos (p. 444-445).

São estas as premissas, portanto, de um diálogo intercultural sobre a dignidade humana que podem levar, eventualmente, por meio da hermenêutica diatópica, a uma "concepção mestiça de direitos humanos, uma concepção que, em vez de recorrer a falsos universalismos, se organiza como uma constelação de sentidos locais, mutuamente inteligíveis, e que se constitui em redes de referências normativas capacitantes" (SANTOS, 2003b, p. 443).

Conclui-se que o objetivo da hermenêutica diatópica não é atingir a completude, algo inatingível, mas, "pelo contrário, ampliar ao máximo a consciência de incompletude mútua através de um diálogo que se desenrola, por assim dizer, com um pé numa cultura e outro, noutra. Nisto reside o seu carácter diatópico" (SANTOS, 2003b, p. 444). Destarte, aumentar a consciência de incompletude cultural até ao seu máximo possível é um objetivo essencial para a construção de uma cosmovisão multicultural de direitos humanos.

\subsubsection{Herrera Flores e o diálogo intercultural}

Segundo crítica de Herrera Flores, a visão universalista acaba tornando-se um universalismo de partida, ${ }^{26}$ em que os direitos humanos são aqueles previamente escolhidos pelas nações hegemônicas, sendo impostos às demais. Por outro lado, "têm surgido vozes que exigem uma volta ao local, como reação compreensível diante dos desmandos e abusos de tal colonialismo conceitual" (FLORES, 2009c, p. 160). Para ele, no entanto, o relativismo constrói outro universalismo, o de linhas/retas paralelas, pois cada cultura acredita ser a sua visão a mais correta, e fecha-se a outras, impedindo o indivíduo de ter conhecimento de outras abordagens do mundo - outras cosmovisões - e gerando uma perspectiva separatista. Nega-se a possibilidade de crítica e criam-se diversas visões universais, que não se cruzam nem se

\footnotetext{
26 "Estamos, pois, ante uma racionalidade que universaliza um particularismo: o do modo de produção e de relações sociais capitalistas, como se fosse o único modo de relação humana. A racionalidade formal culmina em um tipo de prática universalista que poderíamos qualificar de universalismo de partida, a priori, um pré-juízo ao qual deve adaptar-se toda a realidade (FLORES, 2009c, p. 160).
} 
conversam (paralelas), o que não auxilia a resistência, e sim desagrega. Assim, "o localismo reforça a categoria de distinção, de diferença radical, com o que, em última instância, acaba defendendo o mesmo que a visão abstrata do mundo: a separação entre nós e eles, o desapreço pelo outro, a ignorância sobre o que nos faz idênticos é a relação com os outros" (FLORES, 2009c, p. 162).

Para Flores (2009c), deve-se pensar a partir de uma racionalidade de resistência:

Uma racionalidade que não nega que é possível chegar a uma síntese universal das diferentes opções relativas aos direitos. E tampouco descarta a virtualidade das lutas pelo reconhecimento das diferenças étnicas ou de gênero. O que negamos é considerar o universal como um ponto de partida ou um campo de desencontros. Ao universal há de se chegar - universalismo de chegada ou de confluência - depois (não antes) de um processo conflitivo, discursivo de diálogo ou de confrontação no qual cheguem a romper-se os prejuízos e as linhas paralelas (p. 163).

Com base nesse pensamento, o autor atinge um universalismo de chegada ou de confluência, de entrecruzamento, de mesclas, um universalismo impuro, uma prática social híbrida, ${ }^{27}$ que propõe a inter-relação e não a superposição, e que "não aceita a visão microscópica que parte de nós mesmos, no universalismo de partida ou de retas paralelas" (FLORES, 2009c, p. 165). Segundo o autor, essa nova cultura de direitos deve recorrer, em seu seio, à universalidade das garantias e ao respeito pelo diferente, sendo complexa. "Seu esquema respeita a seguinte estrutura: Visão complexa - racionalidade de resistência - prática intercultural" (FLORES, 2009c, p. 165). Não deve ficar limitado, porém, ao necessário reconhecimento do outro; é preciso também empoderar os excluídos e trabalhar para a criação de mediações políticas, institucionais e jurídicas que garantam esse reconhecimento e transferência de poder (FLORES, 2009c, p. 10-11).

O método para tanto é o diálogo intercultural, que busca construir uma cultura dos direitos que recorra, no seu bojo, à universalidade das garantias e ao respeito pelo diferente, com vistas a superar a polêmica entre o pretenso universalismo dos direitos e a aparente particularidade das culturas, pois ambos são produtos de visões reducionistas da realidade. Busca, portanto, alcançar um catálogo de valores (não etnocêntricos) que tenha a concordância de todos os participantes.

Ainda conforme o autor, não é válido rejeitar todas as ideias ocidentais sobre direitos humanos, como se fossem todas elas produtos do colonialismo e do imperialismo, mas também é necessário ter em mente que ambas as cosmovisões clássicas "partem de universalizações e de exclusões; não partem de processos que nos permitiriam chegar ao conjunto de generalidades que todos poderíamos compartilhar" (FLORES, 2009c, p. 165). Desse modo,

\footnotetext{
27 “Já que nada é hoje puramente uma só coisa [...] Uma prática, pois, criadora e re-criadora de mundos" (FLORES, 2009c, p. 166).
} 


\section{Humanos e \\ Democracia}

damos forma ao único essencialismo válido para uma visão complexa do real: o de criar condições para o desenvolvimento das potencialidades humanas, o de um poder constituinte difuso que faça a contraposição, não de imposições ou exclusões, mas de generalidades compartidas às que chegamos (de chegada), e não a partir das quais partimos (de saída) (FLORES, 2009c, p. 149).

Logo, o universalismo de confluência ou de chegada é que assegurará a legitimidade do processo de construção de parâmetros internacionais mínimos voltados à proteção dos direitos humanos, fomentado pelo ativo protagonismo da sociedade civil internacional, a partir de demandas e reivindicações morais (PIOVESAN, 2007, p. 149).

\section{SEMELHANÇAS E DIFERENÇAS ENTRE AS TEORIAS DE BOAVENTURA DE SOUSA SANTOS E JOAQUÍN HERRERA FLORES}

Analisadas as teorias dos dois autores em separado, problematiza-se: Até que ponto as teorias de Boaventura de Sousa Santos e Joaquín Herrera Flores mostram similitudes e diferenças como formas de fundamentar os direitos humanos ante o multiculturalismo?

As semelhanças entre as teorias de ambos os autores estudados são muitas, como no método para se chegar à solução (que para Herrera Flores é a racionalidade de resistência e o diálogo intercultural, enquanto para Santos é a hermenêutica diatópica), por ambos ressaltarem a globalização como um dos fatores principais para as novas visões multiculturais dos direitos humanos, bem como por partirem do pressuposto da insuficiência das visões clássicas e, por fim, a busca por uma linha que agregue, e não separe, respeitando as particularidades de cada cultura, mas não as levando a extremos, ao mesmo tempo em que se procura uma resposta conciliatória.

Há, todavia, diferenças entre suas teorias, como o enfoque dado ao conceito de dignidade humana. Para Santos, o conceito de direitos humanos assenta-se num bem conhecido conjunto de pressupostos, todos eles tipicamente ocidentais, como o que o indivíduo possui uma dignidade absoluta e irredutível que tem de ser defendida da sociedade ou do Estado. Dignidade, portanto, como conhecemos, é um conceito de construção eminentemente ocidental. ${ }^{28}$ Assim, todas as culturas são incompletas e problemáticas nas suas concepções de dignidade humana, havendo, nas diferentes versões de dignidade, "algumas mais amplas do que outras, algumas com um círculo de reciprocidade mais largo do que outras, algumas mais abertas a outras culturas do que outras" (SANTOS, 2003b, p. 442), necessitando-se definir qual delas propõe um círculo de reciprocidade mais amplo. Por outro lado, para Herrera Flores a dignidade é um objetivo que deve ser buscado com os direitos humanos, que visam a efetivá-la, não ressaltando ser um conceito de matiz ocidental. Logo, enquanto para Santos o conceito de dignidade como difundido é não só incerto, como até mesmo imposto pela visão

\footnotetext{
28 "Uma vez que todos estes pressupostos são claramente ocidentais e facilmente distinguíveis de outras concepções de dignidade humana em outras culturas, teremos de perguntar por que motivo a questão da universalidade se transformou em uma das características marcantes dos direitos humanos" (SANTOS, 2003b, p. 439).
} 
hegemônica de direitos humanos, para Herrera Flores é um objetivo comum (não sendo imposto pelo Ocidente) que deve ser buscado, ${ }^{29}$ embora ele reconheça que o conceito de dignidade também é variável.

Ainda, há uma diferenciação de nomenclatura: Santos denomina sua solução conciliatória de direitos humanos de multicultural; já Herrera Flores defende que não se deve buscar o multicultural, mas, sim, o intercultural. Em uma análise mais detida, porém, percebe-se que tal diferença é apenas aparente, pois os multiculturalismos de ambos os autores são convergentes e com viés progressistas, encaixando-se no que parte da doutrina chama de interculturalismo, sendo construídos de forma convergentes.

\section{CONSIDERAÇÕES FINAIS}

Verificou-se que as cosmovisões clássicas do universalismo e do relativismo, como Herrera Flores teoriza, acabam ensejando um universalismo de ponto de partida e um universalismo de linhas paralelas respectivamente, o que afasta o diálogo intercultural, que, pela multiplicidade de etnias e países diversos, é riquíssimo e não deve ser desprezado. Ainda, torna-se claro que a cosmovisão universalista assume como parâmetro de direitos humanos o viés adotado por países ditos de "primeiro mundo" ou "desenvolvidos", desprezando os direitos humanos na perspectiva dos países subdesenvolvidos ou periféricos, o que se denominou "canibalismo cultural". Demonstrou-se, portanto, a ineficiência das cosmovisões clássicas em fundamentar a contento os direitos humanos em uma sociedade globalizada - ou, como sustentado por Boaventura de Sousa Santos, com tantas globalizações diversas.

Teoriza-se o multiculturalismo como uma nova cosmovisão que surge para fundamentar os direitos humanos, visando a ir além dos estreitos caminhos das cosmovisões clássicas. Para tanto, ciente dos diversos significados de multiculturalismo, inclusive na divisão estabelecida por McLaren, adotou-se o multiculturalismo progressista ou emancipatório, que converge com o significado de interculturalismo (para a corrente que faz essa diferenciação de conceitos), e, sob as perspectivas de Boaventura de Sousa Santos e Joaquín Herrera Flores, investigados ao longo do artigo, entende-se como um caminho apto a solucionar o embate entre as cosmovisões clássicas do universalismo e do relativismo.

Constatou-se que, dentre as teorias objetos de pesquisa, existem mais semelhanças do que diferenças. Dentre as similitudes, citam-se, respectivamente (primeiro Santos, e depois Herrera Flores): a perspectiva emancipatória e a racionalidade de resistência como pontos de partida de suas teorias, a hermenêutica diatópica e o diálogo intercultural como métodos para se chegar à solução e o multiculturalismo contra-hegemônico ou cosmopolita e o universalismo de confluência como propostas conciliatórias. Dentre possíveis diferenças, apresentou-se a amplitude da dignidade humana, pois, para Santos, é mais um conceito hegemônico imposto pela visão ocidental, que deve ser analisada em sua incompletude; já Herrera Flores não destaca isso, apresentando a dignidade humana como objetivo a ser alcançado. Na classi-

\footnotetext{
29 "Os direitos humanos são os meios discursivos, expressivos e normativos que pugnam por reinserir os seres humanos no circuito de reprodução e manutenção da vida, permitindo-nos abrir espaços de luta e de reivindicações. São processos dinâmicos que permitem a abertura e a conseguinte consolidação e garantia de espaços de luta pela particular manifestação da dignidade da pessoa humana" (FLORES, 2009a, p. 10).
} 


\section{Humanos e \\ Democracia}

ficação de suas teorias multiculturalidade ou interculturalidade, conclui-se que esta diferença é apenas aparente, pois os multiculturalismos de ambos os autores são convergentes e com viés progressista.

Destacou-se a importância de se buscar um estudo da fundamentação dos direitos humanos, embora não baste fundamentá-los, uma vez que "é preciso buscar as melhores medidas para torná-los efetivos, pois só assim se alcançará uma verdadeira proteção de todos os indivíduos [...] e, consequentemente, a paz mundial" (GUIMARÃES, 2007, p. 65).

Por fim, ressalta-se que, na linha defendida por Boaventura de Sousa Santos, "não é simplesmente de um conhecimento novo que necessitamos; o que necessitamos é de um novo modo de produção de conhecimento. Não necessitamos de alternativas, necessitamos é de um pensamento alternativo às alternativas". Nessa esteira, busca o presente artigo propor uma reflexão epistemológica, adotando referenciais teóricos de autores que se encaixam melhor no contexto latino-americano em que o Brasil se insere. Assim, "em nossos países se vê cada vez mais claro que a compreensão do mundo é muito mais ampla que a compreensão ocidental", e, nesse sentido, destaca-se que o principal problema "para quem vive no Sul é que as teorias estão fora de lugar: não se ajustam realmente a nossas realidades sociais. Sempre nos tem sido necessário indagar uma maneira pela qual a teoria se ajuste a nossa realidade" (SANTOS, 2007, p. 23). ${ }^{30}$ Para este objetivo, procurou este estudo contribuir.

\section{REFERÊNCIAS}

ASTRAIN, R. Ética intercultural e pensamento latino-americano. In: SIDEKUM, A. Alteridade e multiculturalismo. Ijuí: Editora Unijuí, 2003.

BOBBIO, N. A era dos direitos. Rio de Janeiro: Campus, 1992.

CASTORIADIS, C. A instituição imaginária da sociedade. São Paulo: Editora Paz e Terra, 2000.

COELHO, Inocêncio Mártires. Apresentação. In: ZAGREBELSKY, Gustavo. A Crucificação e a Democracia. São Paulo: Editora Saraiva, 2011, p. 11.

COPELLI, G. M. Resenha da obra teoria crítica dos direitos humanos: os direitos humanos como produtos culturais, de Joaquín Herrera Flores. Revista Direitos Humanos e Democracia, Ijuí: Editora Unijuí, ano 3, v. 2, 2014. DONNELLY, J. Universal human rights in theory and practice. New York: Cornell University Press, 1989.

FLORES, J. H. A (re)invenção dos direitos humanos. Florianópolis: Fundação Boiteux, 2009a.

FLORES, J. H. Direitos humanos, interculturalidade e racionalidade de resistência. In: FLORES, J. H. $A$ (re)invenção dos direitos humanos. Florianópolis: Fundação Boiteux, 2009b.

FLORES, J. H. Teoria crítica dos direitos humanos: os direitos humanos como produtos culturais. Rio de Janeiro: Editora Lumen Juris, 2009c.

\footnotetext{
${ }^{30}$ Continuando o raciocínio de Santos (2007, p. 23-25): “[...] a compreensão do mundo é muito mais ampla que a ocidental. [...] provavelmente, o mais preocupante no mundo de hoje é que tanta experiência social fique desperdiçada, porque ocorre em lugares remotos. Experiências muito locais, não muito conhecidas nem legitimadas pelas ciências sociais hegemônicas, são hostilizadas pelos meios de comunicação social, e por isso têm permanecido invisíveis, 'desacreditadas'. A meu ver, o primeiro desafio é enfrentar esse desperdício de experiências sociais que é o mundo; e temos algumas teorias que nos dizem não haver alternativa, quando na realidade há muitas alternativas. [...] "Com efeito, a racionalidade que domina no Norte tem tido uma influência enorme em todas as nossas maneiras de pensar, em nossas ciências, em nossas concepções da vida e do mundo. A essa racionalidade - seguindo Gottfried Leibniz - eu chamo indolente, preguiçosa. É uma racionalidade que não se exerce muito, que não tem necessidade de se exercitar bastante, daí por que fiz este livro publicado na Espanha, chamado 'A crítica da razão indolente: contra o desperdício da experiência'. Então, o que estou tentando fazer aqui hoje é uma crítica à razão indolente, preguiçosa, que se considera única, exclusiva, e que não se exercita o suficiente para poder ver a riqueza inesgotável do mundo. Penso que o mundo tem uma diversidade epistemológica inesgotável, e nossas categorias são muito reducionistas."
} 
GUIMARÃES, M. A. Fundamentação dos direitos humanos: relativismo ou universalismo? In: PIOVESAN, Flávia (coord.). Direitos Humanos. Curitiba: Juruá, 2007. p. 65. Vol. 1.

KERSTING, W. Universalismo e Direitos Humanos. Porto Alegre: EDIPUCRS, 2003.

LACERDA, D. O. Universalismo e relativismo cultural: a consolidação do espaço público para o início de um consenso. In: PIOVESAN, Flávia et al. (coord.). Direitos humanos na ordem contemporânea: proteção nacional, regional e global. Curitiba: Juruá Editora, 2010, p. 33-52. Vol. III.

LEGROS, P.; MONNEYRON, F.; RENARD, J.; TACUSSEL, P. Sociologia do imaginário. Porto Alegre: Editora Sulina, 2007.

LINDGREN ALVES, J. A. Abstencionismo e intervencionismo no sistema de proteção das Nações Unidas aos direitos humanos. Revista Política Externa, v. 3, n. 1, p. 97-106, jun. 1994.

MAGALHÃES FILHO, G. B. Notas de aula da disciplina Estudos do Imaginário Jurídico: distinção e relação entre conceitos respeitantes ao Imaginário. 2012. [S.I.]: [s.n.].

McLAREN, P. Multiculturalismo crítico. São Paulo: Cortez Editora, 1997.

PIOVESAN, F. Direitos humanos e o direito constitucional internacional. 7. ed. São Paulo: Editora Saraiva, 2007.

RUIZ, C. B. O paradoxo do imaginário. São Leopoldo: Editora Unisinos, 2003.

SANTOS, B. de S. Dilemas do nosso tempo: globalização, multiculturalismo e conhecimento. Currículo sem Fronteiras, v. 3, n. 2, p. 5-23, jul./dez. 2003a.

SANTOS, B. de S. Os direitos humanos na zona de contato entre globalizações rivais. Revista Brasileira de Ciências Criminais, v. 15, n. 64, p. 313-337, jan./fev. 2007.

SANTOS, B. de S. Os direitos humanos na pós-modernidade. In: Direito e sociedade, Coimbra, n. 4, mar. 1989.

SANTOS, B. de S. Por uma concepção multicultural dos direitos humanos. In: SANTOS, B. S. (org.). Reconhecer para libertar: os caminhos do cosmopolitismo multicultural. V. III: reinventar a emancipação social: para novos manifestos. Rio de Janeiro: Civilização Brasileira, 2003b.

SANTOS, B. de S. Renovar a teoria crítica e reinventar a emancipação social. São Paulo: Boitempo, 2009.

SANTOS, B. de S.; NUNES, J. A. Introdução: para ampliar o cânone do reconhecimento, da diferença e da igualdade. In: SANTOS, Boaventura de Sousa (org.). Reconhecer para libertar: os caminhos do cosmopolitismo multicultural. Rio de Janeiro: Civilização Brasileira, 2003.

SIRE, J. W. O universo ao lado. 1. ed. São Paulo: United Press, 2001.

SORIANO, R. Interculturalismo. Entre liberalismo y comunitarismo. Córdoba: Almuzara, 2004.

VALLESCAR PALANCA, D. de. Hacia una racionalidad intercultural: cultura, multiculturalismo e interculturalidad. 2000. 454 f. Tese (Maestría) - Universidad Complutense de Madrid, Facultad de Filosofía, 2000.

VINCENT, R. J. Human Rights and International Relations. Cambridge: Cambridge University Press, 1986.

ZAGREBELSKY, G. A crucificação e a democracia. São Paulo: Editora Saraiva, 2011. 